\title{
Promotion of platelet aggregation by sera from brucellosis patients with antiphosphatidylcholine antibodies
}

\author{
M. ÁNGELES CASAO, RAMÓN DÍAZ, ANTONIO ORDUÑA* and CARLOS GAMAZO \\ Departamento Microbiología. Universidad de Navarra, Clínica Universitaria de Navarra. 31080, Pamplona and \\ * Departamento Microbiología, Hospital Universitario, Facultad de Medicina, Universidad de Valladolid, Spain
}

\begin{abstract}
Results obtained in this study suggest that in human brucellosis there is an antibody response against platelet-activating factor (PAF) and phosphatidylcholine (PC). The specificity of the antiphospholipid response was determined by inhibition assays. The PAF molecule was able to inhibit the anti-PC activity of the brucellosis-control serum. This inhibition capacity of PAF was similar to that of the phosphorylcholine (PYC) group. These results suggest that the inhibition activity could be attributed to the PYC group present in both PAF and PC molecules. Consequently, these findings support an immunodominant role of PYC in the antiphospholipid response of brucellosis. Furthermore, sera from patients infected with Brucella organisms were able to cause platelet aggregation, as were brucella phospholipids, suggesting a possible role of the antiphospholipid antibodies and phospholipids in the inflammatory response in brucellosis.
\end{abstract}

\section{Introduction}

Platelet activating factor (PAF) is a biologically active phospholipid that has several functions as well as platelet activation, including activation of polymorphonuclear leucocytes (PMNLs) and other leucocytes, alteration of vascular permeability and blood pressure, and contraction stimulation, [1]. It acts under normal physiological conditions but also mediates some pathological responses, most significantly in inflammatory and allergic processes. Evidence of these functions is found in its detection in blood samples of patients with arthritis [1-4]. The activation mechanism is still not fully known; however, it has been demonstrated that PAF acts as an intracellular and intercellular messenger, activating the target cells $[5,6]$.

Structurally, PAF is an ether-phosphorylcholine (etherPYC) (acetyl-glyceryl-phosphorylcholine) that contains a fatty acid linked to $\mathrm{C}_{1}$ by an ether linkage, an acetyl residue in $\mathrm{C}_{2}$ and a phosphorylcholine (PYC) residue in $\mathrm{C}_{3}$ [7]. The acetyl group is implicated in the PAF

Received 27 Dec. 2000; revised version accepted 4 May 2001.

Corresponding author: Dr C. Gamazo (e-mail: cgamazo@, unav.es). aggregating activity, although the PYC region is also critical for its biological activity [8].

Brucellosis is a systemic infection caused by gramnegative bacteria of the genus Brucella, which is characterised by the development of focal disease, inflammatory response and frequent arthritic processes [9]. One of the most peculiar characteristics of the membrane structure of Brucella spp. is the presence of phosphatidylcholine (PC) on its outer membrane [10], which is rare in most gram-negative bacteria. The structural relationship between $\mathrm{PC}$ and PAF [1], together with the presence of anti-PC antibodies in patients suffering from brucellosis [11], suggest that PC and anti-PC antibodies could play some role in those biological processes. Therefore, this study first investigated the presence of anti-PAF antibodies in sera from patients with brucellosis. Then, due to its structural similarity to PAF, brucella PC was investigated as an aggregating factor in vitro.

\section{Materials and methods}

\section{Subjects and sera}

Seven patients who were admitted to the Clínica Universitaria de Navarra (Pamplona, Spain) were included in the study. The diagnostic criteria were: (i) the isolation of Brucella spp. from blood or other body 
fluid or tissue specimens; and (ii) the presence of compatible clinical findings (fever, sweats, arthralgia, headache, weight loss, hepatomegaly, splenomegaly or signs of focal disease) together with the appearance of specific antibodies to Brucella at significant titres. Significant titres were considered to be a seroagglutination test titre $\geqslant 160$, or a Coombs test titre $\geqslant 320$. After diagnosis, five serum samples were taken from each patient at various times: 15 days after initiating treatment, when treatment was completed and during the post-treatment follow-up, quarterly for a year.

The control sera used in the study were obtained by: (1) mixing sera from 10 patients diagnosed with brucellosis on the day of the onset of the disease (brucellosis-control); and (2) mixing sera from 10 healthy donors (negative control).

\section{Reagents and brucella extract}

PAF, egg PC and phosphorylcholine were obtained from Sigma-Aldrich Corporation (St Louis, MO, USA).

Brucella phospholipids were obtained from the rough strain B. melitensis 115 by the procedure described previously [10]. Briefly, flasks containing Trypticase Soy Broth (bioMérieux, Marcy l'Etoile, France) were inoculated with the strain and then incubated for $48 \mathrm{~h}$ at $37^{\circ} \mathrm{C}$. After centrifugation at $7500 \mathrm{~g}$ for $15 \mathrm{~min}, 5 \mathrm{~g}$ of packed cells were dispersed in chloroform:methanol:water (4:5:10, v:v:v) and shaken for $20 \mathrm{~min}$. Then, a fresh mixture of chloroform and water $(1: 1, v: v)$ was added, shaken for $30 \mathrm{~min}$ and filtered $(0.8-\mu \mathrm{m}$ cellulose acetate membrane filters). The residue on the filter was added to $10 \mathrm{ml}$ of chloroform, and dried under a nitrogen flow (dry residue of brucella phospholipids, PL-brucella).

\section{ELISA-PC and ELISA-PAF}

The ELISA was performed as described previously [11] with $5 \mu \mathrm{g}$ of the antigen (egg PC or PAF) dissolved in PBS (10 mM phosphate-buffered saline, pH 7.2) $(50 \mu \mathrm{g} / \mathrm{ml})$ applied to ELISA microplates (Maxisorp, Nunc). After incubation at $37^{\circ} \mathrm{C}$ for $24 \mathrm{~h}$, the solution was tipped off and the microplates were washed four times with PBS plus Tween-20 0.05\% (PBST). Serum samples were first diluted in a separate test tube in PBST before addition to the ELISA plates. The plates were incubated at $37^{\circ} \mathrm{C}$ for $4 \mathrm{~h}$. Two different antihuman immunoglobulin peroxidase conjugates were used: rabbit anti- $\alpha$ (Pierce) and $\gamma$ (Nordic) chains, diluted 1 in 1000 in PBST. After incubation for $30 \mathrm{~min}$ at $37^{\circ} \mathrm{C}$, the plates were washed and developed by incubation for $20 \mathrm{~min}$ at room temperature with $2,2^{\prime}$ azino-bis-3-ethylbenzothiazoline-6-sulphonic acid diammonium salt (Sigma) $0.01 \%$ in $0.1 \mathrm{M}$ citrate buffer (pH 4.0) containing $\mathrm{H}_{2} \mathrm{O}_{2} \quad 0.01 \%$. The colorimetric values were determined by measuring the optical density (OD) at $405 \mathrm{~nm}$; samples with $\mathrm{OD}_{405} \geqslant 550$ were considered positive [11].

\section{Inhibition assays}

Inhibition of antibody binding to PC was performed as described by Harris et al. [12] with some modifications. Serum samples (diluted 1 in 100 in PBS) were pre-incubated with PAF, egg PC or PYC at different concentrations $(5,1,0.5$ or $0.1 \mathrm{mg} / \mathrm{ml}$ of serum) for $4 \mathrm{~h}$ at $37^{\circ} \mathrm{C}$, and then overnight at $4^{\circ} \mathrm{C}$ with constant mixing. The samples were then centrifuged at $21000 \mathrm{~g}$ for $20 \mathrm{~min}$ to eliminate the immunocomplex. The inhibition assay with each substance was repeated twice. The new binding activities in 'ELISA-PC' $\left(\mathrm{OD}_{405}\right)$ were compared with those of the control sera. The results were reported as percentage inhibition, calculated as follows: percentage inhibition $=\left[\left(\mathrm{OD}_{405}\right.\right.$ positive control sample inhibited- $\mathrm{OD}_{405}$ negative control sample $) /\left(\mathrm{OD}_{405}\right.$ positive control sample $-\mathrm{OD}_{405}$ negative control sample) $] \times 100$.

\section{In-vitro platelet aggregation assay}

Platelets were obtained from $15 \mathrm{ml}$ of human blood taken from healthy donors, at the time of the assay, into siliconised glass tubes containing trisodium citrate $3.8 \%(9: 1, \mathrm{v}: \mathrm{v})$ to avoid coagulation (Becton Dickinson, Franklin Lakes, NJ, USA). After centrifugation at $800 \mathrm{~g}$ for $10 \mathrm{~min}$ at $4^{\circ} \mathrm{C}$, the upper portion was recovered, i.e., 'platelet-rich plasma' (PRP). A second centrifugation $\left(2000 \mathrm{~g}, 5 \mathrm{~min}, 4^{\circ} \mathrm{C}\right)$ separated the 'platelet-poor plasma' (PPP) from the lower portion. PPP was added to PRP until a platelet concentration ranging from $2.5 \times 10^{5}$ to $3.5 \times 10^{5} / \mu 1$ was obtained; $500 \mu \mathrm{l}$ was placed in each cuvette and $50 \mu \mathrm{l}$ of aggregating agent were added. The platelet aggregation process was monitored for $5 \mathrm{~min}$ with an aggregometer (Aggrecorder II) that measures light transmission. Adenyl diphosphate (ADP; Menarini Diagnostics, Florence, Italy) $2 \mu \mathrm{g} / \mathrm{ml}$ was used as a positive control for induction of platelet aggregation. The inhibitory capacity of the sera (brucellosis-control and the negative-control) on the PAF aggregating activity was studied by incubating $50 \mu \mathrm{l}$ of PAF $(1 \mu \mathrm{g} / \mathrm{ml})$ with $50 \mu \mathrm{l}$ of the control serum $\left(3 \mathrm{~h}, 37^{\circ} \mathrm{C}\right) .50 \mu \mathrm{l}$ of this solution were then added to each cuvette and the platelet aggregation was monitored for $5 \mathrm{~min}$. The percentage aggregating activity of the solution was determined with respect to the aggregation induced by the same concentration of PAF. Similarly, the aggregating capacity of the same control sera on platelets (undiluted sera) was also studied.

Experiments were run in quintuplicate. The statistical significance of differences was determined after variance analysis by comparison of group means by Dunnett's procedure. 


\section{Results and discussion}

The detection of anti-PC and anti-PAF antibodies was determined by ELISA as described previously [11]. The results indicated that an anti-PC response was accompanied by either IgA or IgG anti-PAF antibodies (Table 1). To confirm this parallel response, the evolution of the anti-PC and anti-PAF responses was compared in a group of patients with brucellosis. The results demonstrated that both responses followed a similar evolution with time (data not shown). Similarly, the presence of platelet-aggregating antiphospholipid (PL) antibodies in patients with systemic lupus erythematosus (SLE) and antiphospholipid syndrome has already been discussed and proposed by other authors [13-16].

The specificity of the anti-PL response was determined by inhibition assays, absorbing control sera (patients with brucellosis and healthy donors diluted 1 in 100 in PBS) with different substances. The inhibition of antiPC activity in ELISA was higher when the brucellosiscontrol was pre-incubated with the PAF than with the PC molecule. The serum sample was absorbed twice with $\mathrm{PC}$ to reach the same level of inhibition as PAF (70\%). Furthermore, the inhibition capacity of PAF was similar to that of the PYC group (PAF is an ether PYC) [7], suggesting that such activity could be attributed to its PYC group, as well as in PC (ether-PYC) [17]. Therefore, these results support an immunodominant role of PYC in the anti-PL and anti-PAF responses in brucellosis.

It has been demonstrated that PC can undergo a series of transformations during the inflammatory progression. First, phospholipase $\mathrm{A}_{2}$ associated with LDL or expressed by different cell types during inflammatory processes hydrolyses the fatty acid of the $\mathrm{C}_{2}$ producing a smooth PC; secondly, when PC presents polyunsaturated fatty acids in the $\mathrm{C}_{2}$ (this is the case with brucella PC) [17] it is oxidised, causing a short-chain PC. The molecules obtained during these processes (smooth PC and oxidised short chain PC) have similar structures to PAF. Consequently, it is possible that the PC of Brucella undergoes a series of transformations generating a structure similar to PAF. According to this, the antibody response detected against PAF may be the result of a specific anti-PAF response, and not just due to cross-reactions between $\mathrm{PC}$ and PAF.

Platelet aggregation assays were performed to ascertain the possible biological consequences of the presence of anti-PAF antibodies in patients with brucellosis. Contrary to what was initially expected, when the brucellosis-control serum was pre-incubated with PAF, instead of causing a reduction of the percentage aggregation by PAF neutralisation, it caused no appreciable change (100\% versus $107 \%$, respectively). In fact, the brucellosis-control serum caused platelet aggregation, while the negative-control serum did not have any effect ( $73 \%$ versus $3 \%$, respectively; Table 2 ). Brucellosis-negative serum significantly reduced the PAF activity $(67 \%$ versus $100 \%, \mathrm{p}<0.05)$. This indicates that some component in sera could block PAF aggregation, although there are no data to confirm this hypothesis. In this sense, it is possible that the aggregative activity detected with the brucellosis-positive serum $(73 \%)$ could neutralise such a blocking

Table 1. Serological and clinical characteristics of the patients with brucellosis

\begin{tabular}{|c|c|c|c|c|c|c|}
\hline \multirow{2}{*}{$\begin{array}{l}\text { Patient } \\
\text { no. }\end{array}$} & \multicolumn{2}{|c|}{ ELISA-PC } & \multicolumn{2}{|c|}{ ELISA-PAF } & \multirow{2}{*}{$\begin{array}{l}\text { Evolution of } \\
\text { disease (days) }\end{array}$} & \multirow[b]{2}{*}{ Clinical manifestations } \\
\hline & $\mathrm{IgG}$ & $\operatorname{IgA}$ & $\operatorname{IgG}$ & $\operatorname{IgA}$ & & \\
\hline 27 & - & + & + & + & $\leqslant 15$ & Myalgia, arthralgia \\
\hline 28 & + & - & + & - & $\leqslant 15$ & Arthralgia \\
\hline 29 & - & - & - & - & $\leqslant 15$ & Orchitis \\
\hline 30 & + & + & + & + & $\leqslant 15$ & Arthralgia \\
\hline 31 & - & - & - & - & 180 & Arthralgia \\
\hline 33 & + & - & + & - & 96 & Arthralgia \\
\hline 34 & + & + & + & - & $\leqslant 15$ & Arthralgia \\
\hline
\end{tabular}

Table 2. Platelet aggregation with the different agents assayed $\left(5 \mathrm{~min}, 37^{\circ} \mathrm{C}\right)$

\begin{tabular}{lcc}
\hline Agent & $\begin{array}{c}\text { Mean (SD) percent } \\
\text { platelet aggregation* }\end{array}$ & $\begin{array}{c}\text { Relative } \\
\text { aggregation }^{\dagger}\end{array}$ \\
\hline ADP $(2 \mu \mathrm{g} / \mathrm{ml})$ & $85.4(1.8)$ & 141.7 \\
Phospholipids B. melitensis $(1 \mu \mathrm{g} / \mathrm{ml})^{*}$ & $50.0(4.0)$ & 83 \\
PAF $(1 \mu \mathrm{g} / \mathrm{ml})$ & $60.2(1.8)$ & 100 \\
Pool sera from brucellosis patients (positive control) & $43.6(7.6)$ & 73 \\
Pool sera healthy donors (negative control) & $1.8(0.8)$ & 3 \\
PAF $(1 \mu \mathrm{g} / \mathrm{ml})+$ brucellosis-positive serum & $63.6(9.6)$ & 107 \\
PAF $(1 \mu \mathrm{g} / \mathrm{ml})+$ brucellosis-negative serum & $40.2(8.1)$ & 66.7 \\
\hline
\end{tabular}

\footnotetext{
* Mean (SD) of five experiments.

${ }^{\dagger}$ Activity compared to aggregation by PAF $1 \mu \mathrm{g} / \mathrm{ml}$.

Equivalent to PC $0.3 \mu \mathrm{g} / \mathrm{ml}$.
} 
effect $(107 \%$, PAF + brucellosis-positive serum versus $100 \%$, PAF alone).

Furthermore, the structural similarity between PC and PAF mentioned above suggests that the PC of Brucella spp. could directly act analogously to PAF and have an agonistic activity after binding to PAF receptors. In fact, other phospholipids that activate PAF receptors have been described, although in general they are less potent than PAF itself, re-emphasising the importance of the residues in $\mathrm{C}_{2}$ and $\mathrm{C}_{1}$. Thus, Stremler et al. [18] demonstrated that the oxidation of $\mathrm{PC}$ that contains a polyunsaturated fatty acid in $\mathrm{C}_{2}$ (Brucella-PC has a polyunsaturated fatty acid in $\mathrm{C}_{2}$, lactobacillic acid) produces a structure with high activity similar to PAF. Similarly, Smiley et al. [8] demonstrated that oxidised derivatives of PC activate human PMNLs via interaction with the PAF receptor. Therefore, it is possible that the action of phospholipase $\mathrm{A}_{2}$ and the oxygen radicals, generated after the activation of phagocytic cells by Brucella transform brucella PC into molecules with a biological activity similar to PAF. Moreover, the results obtained in aggregation assays support this hypothesis, as brucella phospholipids caused $50 \%$ platelet aggregation at a concentration of $1 \mu \mathrm{g} / \mathrm{ml}$ ( $83 \%$ activity, in comparison to aggregation by PAF) (Table 2). In contrast, the egg PC did not show any activity.

Taken together, these results could explain why, on some occasions, patients with brucellosis show an altered pattern of coagulation, although this alteration has not been fully studied $[19,20]$.

A study with a bigger sample of patients is needed to confirm the above hypothesis. In any case, the following sequence of events could be suggested. After a brucella infection, a response mediated by anti-PL antibodies is generated, at least against PC with a PYC dominant group, a chemical group also present in the inflammatory molecule PAF. The inflammatory response also provokes the release of a series of mediators (including PAF), the expression of enzymes such as phospholipase $\mathrm{A}_{2}$ and the release of toxic free oxygen radicals. As brucella PC presents a polyunsaturated fatty acid in $\mathrm{C}_{2}$ it is susceptible to being hydrolysed by phospholipase $\mathrm{A}_{2}$ and oxidised by free oxygen radicals, thus generating molecules with a PAFtype activity that would enhance the inflammatory response. Furthermore, the anti-PC antibodies would also contribute to the inflammatory response by producing platelet aggregation and the subsequent release of new inflammation mediators.

Fellowship support for M.A. Casao from Asociación de Amigos de la Universidad de Navarra is gratefully acknowledged. We also thank Ramón Montes for help with the aggregation analysis.

\section{References}

1. Zimmerman GA, Prescott SM, McIntyre TM. Platelet-activating factor. A fluid-phase and cell-associated mediator of inflammation. In: Gallin JI, Goldsrein IM, Snyderman R (eds) Inflammation: basic principles and clinical correlates, 2nd edn. NewYork, Raven Press. 1992: 149-176.

2. Hilliquin P, Dulioust A, Gregoir C, Arnoux A, Menkes CJ. Production of PAF-acether by synovial fluid neutrophils in rheumatoid arthritis. Inflamm Res 1995; 44: 313-316.

3. Leirisalo-Repo M. The present knowledge of the inflammatory process and the inflammatory mediators. Pharmacol Toxicol 1994; 75 Suppl 2: 1-3.

4. Lupia E, Montrucchio G, Battaglia E, Modena V, Camussi G. Role of tumor necrosis factor-alpha and platelet-activating factor in neoangiogenesis induced by synovial fluids of patients with rheumatoid arthritis. Eur $J$ Immunol 1996; 26: 1690-1694.

5. Benveniste J, Henson PM, Cochrane CG. Leukocyte-dependent histamine release from rabbit platelets. The role of $\mathrm{IgE}$, basophils, and a platelet-activating factor. J Exp Med 1972; 136: $1356-1377$.

6. Prescott SM, Zimmerman G, McIntyre TM. Platelet-activating factor. J Biol Chem 1990; 265: 17381-17384.

7. Benveniste J, Tence M, Varenne P, Bidault J, Boullet C, Polonsky J. [Semi-synthesis and proposed structure of plateletactivating factor (P.A.F.): PAF-acether an alkyl ether analog of lysophosphatidylcholine.] $C R$ Seances Acad Sci D 1979; 289: 1037-1040.

8. Smiley PL, Stremler KE, Prescott SM, Zimmerman GA, McIntyre TM. Oxidatively fragmented phosphatidylcholines activate human neutrophils through the receptor for plateletactivating factor. J Biol Chem 1991; 266: 11104-11110.

9. Winter $\mathrm{H}$, Barlag A. [On the clinical manifestations of brucellosis, 1950-1960.] Med Welt 1966; 40: 2114-2116.

10. Gamazo C, Moriyón I. Release of outer membrane fragments by exponentially growing Brucella melitensis cells. Infect Immun 1987; 55: 609-615.

11. Casao MA, Leiva J, Diaz R, Gamazo C. Anti-phosphatidylcholine antibodies in patients with brucellosis. J Med Microbiol 1998; 47: 49-54.

12. Harris EN, Gharavi AE, Wasley GD, Hughes GRV. Use of an enzyme-linked immunosorbent assay and of inhibition studies to distinguish between antibodies to cardiolipin from patients with syphilis or autoimmune disorders. J Infect Dis 1988; 157: 23-31.

13. Campbell AL, Pierangeli SS, Wellhausen S, Harris EN. Comparison of the effects of anticardiolipin antibodies from patients with the antiphospholipid syndrome and with syphilis on platelet activation and aggregation. Thromb Haemost 1995; 73: $529-534$

14. Escolar G, Font J, Reverter JC et al. Plasma from systemic lupus erythematosus patients with antiphospholipid antibodies promotes platelet aggregation. Studies in a perfusion system. Arterioscler Thromb 1992; 12: 196-200.

15. Khamashta MA, Harris EN, Gharavi AE et al. Immune mediated mechanism for thrombosis: antiphospholipid antibody binding to platelet membranes. Ann Rheum Dis 1988; 47: 849-854.

16. Rauch J, Meng Q-H, Tannenbaum H. Lupus anticoagulant and antiplatelet properties of human hybridoma autoantibodies. J Immunol 1987; 15: 2598-2604.

17. Thiele OW, Schwinn G. The free lipids of Brucella melitensis and Bordetella pertussis. Eur J Biochem 1973; 34: 333-344.

18. Stremler KE, Stafforini DM, Prescott SM, Zimmerman GA, McIntyre TM. An oxidized derivative of phosphatidylcholine is a substrate for the platelet-activating factor acetylhydrolase from human plasma. J Biol Chem 1989; 264: 5331-5334.

19. Aguado Borruey JM, Zurdo Garcia JR, Herraez Garcia J, Diaz Perez F. Brucellosis and disseminated intravascular coagulation. Med Clin (Barc) 1990; 8: 794-795.

20. Crosby E, Llosa L, Miro Quesada M, Carrillo C, Gotuzzo E. Hematologic changes in brucellosis. J Infect Dis 1984; 150: 419-424. 